\title{
Violencia Interpersonal en el Noroeste Argentino Prehistórico: Expresiones Regionales, Socioculturales y Cronológicas
}

\author{
Mario A. Arrieta ${ }^{1}$, Lila Bernardi², María de la Asunción Bordach ${ }^{3}$ y \\ Osvaldo J. Mendonça ${ }^{4}$
}

\section{Resumen}

El análisis osteológico de lesiones atribuibles a violencia constituye una valiosa herramienta para el estudio de conflictos en poblaciones del pasado. Con el objeto de aportar al conocimiento de tales expresiones, se analizan, discuten e interpretan patrones y frecuencias de lesiones atribuibles a violencia en esqueletos correspondientes a distintas secuencias del desarrollo sociocultural del noroeste argentino (NOA). Se relevaron fracturas atribuibles a violencia en 130 individuos mayores de 15 años de edad, pertenecientes a cinco conjuntos óseos provenientes de cinco sitios prehistóricos. Los sitios y materiales asociados corresponden a la serie sociocultural Formativo Inferior,

Desarrollos Regionales, Inca e Hispano-Indígena I. Los resultados ponen de manifiesto la existencia de episodios de violencia en toda la secuencia sociocultural representada. Aunque se observó una mayor prevalencia de individuos afectados en el Hispano-Indígena I (6/35,

$17.14 \%$ ) respecto de los otros, (Formativo Inferior: $1 / 13,7.69 \%$ y Desarrollos Regionales / Inca 7/82, $8.54 \%$ ), las diferencias no resultaron estadísticamente significativas. Se concluye que los episodios de violencia se manifestaron en la región desde tiempos Formativos, verificándose ininterrumpidamente hasta el Hispano-Indígena I. Entre las posibles causas que ocasionaron las lesiones se considera la existencia de conflictos intra e intergrupo.

Palabras clave: bioarqueología, lesiones traumáticas, secuencias socioculturales, noroeste argentino.

\begin{abstract}
The osteological analysis of injuries attributable to violence is a valuable tool for the study of conflict among peoples from the past. In order to contribute to the knowledge of such expressions, patterns of injuries attributable to violence found in complete skeletons (130 individuals over 15 years of age) from five different sites from northwest Argentina (NOA) are analyzed, discussed and interpreted. The osteological evidence and associated materials correspond to four different sociocultural series: Lower Formative, Regional Developments, Inca and Hispanic-Indigenous I. The results show the existence of violence throughout the entire sociocultural sequence here represented.

Although a higher prevalence of affected individuals was observed in the Hispanic-Indigenous I series $(6 / 35,17.14 \%)$, compared to the others (Lower Formative: 1/13, 7.69 \% and Regional Developments / Inca: $7 / 82,8.54 \%$ ), such differences were not statistically significant. We conclude that violence is demonstrated in the region at least since the Lower Formative period, and continues until the Hispano-Indigenous I period. Among the possible causes that led to the registered violence, the existence of intra and inter-group conflicts is considered.
\end{abstract}

Keywords: bioarchaeology, traumatic injuries, sociocultural sequences, northwest Argentina.

Recibido: Julio 2015. Aceptado: Abril 2016

\section{* Introducción}

El ejercicio de la violencia ha sido uno de los medios empleados por las sociedades humanas para resolver $y / 0$ canalizar tensiones tanto intra como inter grupales y ha sido definida como "una poderosa expresión de la interacción social humana" (Schjulting y Wysocki 2005:107). La violencia, tanto letal como no letal, a menudo produce anomalías y/o cambios en los elementos óseos que, en virtud de la naturaleza del registro osteológico, son susceptibles de ser interpretados tanto parcial como completamente (Lovell 1997; Walker 2001; Martin y Harrod 2015). De este modo, la documentación, análisis e interpretación de la violencia interpersonal en el registro óseo humano constituye actualmente uno de los principales tópicos de interés bioarqueológico y, en particular, paleopatológico (Lovell 1997; Jurmain 2001; Walker 2001; Martin y Harrod 2015). Lesiones traumáticas en restos

1 Mario A. Arrieta. Facultad de Cs. Exac., Fco-Qcas y Nats, Universidad Nacional de Río Cuarto (UNRC) - Consejo Nacional de Investigaciones Científicas y Técnicas (CONICET). Laboratorio de Osteología y Anatomía Funcional Humana. Ruta 36, Km 601 (5800), Río Cuarto, Córdoba, Argentina. E-mail: marrieta@exa.unrc.edu.ar

2 Lila Bernardi. Consejo Nacional de Investigaciones Científicas y Técnicas (CONICET). Laboratorio de Osteología y Anatomía Funcional Humana. Ruta 36, Km 601 (5800), Río Cuarto, Córdoba, Argentina. E-mail: lbernardi@exa.unrc.edu.ar

3 María de la Asunción Bordach. Facultad de Cs. Exac., Fco-Qcas y Nats, Universidad Nacional de Río Cuarto (UNRC). Laboratorio de Osteología y Anatomía Funcional Humana. Ruta 36, Km 601 (5800), Río Cuarto, Córdoba, Argentina. E-mail: mbordach@exa.unrc.edu.ar

4 Osvaldo J. Mendonça. Facultad de Cs. Exac., Fco-Qcas y Nats, Universidad Nacional de Río Cuarto (UNRC) - Consejo Nacional de Investigaciones Científicas y Técnicas (CONICET). Laboratorio de Osteología y Anatomía Funcional Humana. Ruta 36, Km 601 (5800), Río Cuarto, Córdoba, Argentina. E-mail: omendonca@exa.unrc.edu.ar 
óseos humanos antiguos, tales como las fracturas en depresión en cráneos y aquellas fracturas provocadas por objetos romos, armas filosas y proyectiles, constituyen excelentes marcadores osteológicos para el estudio de los conflictos sociales en poblaciones prehistóricas (Merbs 1989; Buikstra y Ubelaker 1994; Jurmain y Bellifemine 1997; Lovell 1997; Jurmain 1999, 2001; Walker 2001). Adicionalmente, una lesión total o parcialmente reabsorbida indica la supervivencia al evento traumático. Por el contrario, si no hay ningún tipo de reacción ósea reparadora en el lugar de la herida, es posible inferir que dicha lesión esté muy estrechamente relacionada con las causas que ocasionaron el deceso (Buikstra y Ubelaker 1994; Walker 2001). Además, en caso de observar la presencia de algún tipo de arma o proyectil incrustado en el hueso, o, en su defecto, mediante el análisis de la morfología de las fracturas, se pueden realizar inferencias sobre el arma utilizada, su tecnofactura, sus dimensiones, la materia prima con la cual fue confeccionada, la dirección del ataque, el sitio de impacto e ingreso al organismo y los órganos y elementos óseos que habrían estado comprometidos (Campillo 2001).

En los últimos años, numerosos bioarqueólogos han enfocado sus investigaciones en la evidencia ósea de conflictos mediados por violencia (Lovejoy y Heiple 1981; Walker 1989, 2001; Standen y Arriaza 2000; Jurmain 2001; Torres-Rouff et al. 2005; Torres-Rouff y Costa Junqueira 2006; Lessa y Mendonça de Souza 2007; Murphy et al. 2010; Andrushko y Torres 2011; entre otros). Si bien este abordaje también ha sido adoptado en la Argentina y se han elaborado trabajos donde se encara la violencia interpersonal en poblaciones del pasado, los antecedentes basados en estudios de evidencia y registro sistemáticamente recuperados son relativamente recientes (Barrientos y Gordón 2004; Ammann 2007; Gordón y Ghidini 2007; Flensborg 2011; Gheggi y Seldes 2012; Díaz et al. 2015). En cuanto al noroeste, región que nos ocupa, caben mencionarse el trabajo de Ammann (2007), donde se describen y analizan los indicadores de muerte violenta en esqueletos completos del cementerio de Rincón Chico 21 (Santa María, Catamarca), reestudiados en este trabajo, y la publicación de Gheggi y Seldes (2012), donde se aborda la evidencia de violencia interpersonal para poblaciones de quebrada de Humahuaca y valles Calchaquíes a partir del análisis exclusivo de series craneanas atribuidas por las autoras a los Desarrollos Regionales.
Teniendo en cuenta que es el esqueleto humano considerado en su conjunto quien ofrece mejores potencialidades para brindar información sobre el registro de incidentes violentos, particularmente aquellos en la forma de fracturas, en este trabajo se intenta documentar la frecuencia y el patrón de las lesiones traumáticas atribuidas a sucesos de violencia ocurridos a lo largo de diferentes momentos del desarrollo sociocultural de la región. Para ello se efectuará el examen de cinco conjuntos osteológicos humanos, cuatro provenientes de quebrada de Humahuaca y uno del valle de Santa María o Yocavil meridional. Debido a que la variación temporal representada por los conjuntos considerados abarca desde el Formativo Inferior hasta el Hispano-Indígena inicial, en virtud de las diferentes propuestas teóricas y de los niveles de complejidad estructural entre períodos, nuestra hipótesis es que se observarán diferencias tanto en la expresión como en la frecuencia de lesiones atribuibles a violencia entre la series cronológica y socioculturalmente representadas, pudiéndose llegar a registrar una frecuencia significativamente mayor hacia momentos más tardíos (Desarrollos Regionales / Inca e Hispano-Indígena I). La información proporcionada por nuestro análisis será discutida e interpretada a la luz del conocimiento bioarqueológico, arqueológico y documental actualmente disponible.

\section{Los desarrollos culturales en el NOA}

El noroeste de Argentina (NOA) es una extensa región histórico-geográfica que abarca las actuales provincias de Jujuy, Salta, Catamarca, Tucumán, La Rioja, parte de Santiago del Estero y norte de San Juan. En este vasto y variado escenario geográfico tuvieron lugar el origen y el desarrollo de importantes culturas aborígenes, muchas de ellas directa o indirectamente emparentadas $y / o$ vinculadas por lazos tanto biológicos como socioculturales y ambientales (González y Pérez 1972).

El primer gran lapso de ocupación, es denominado Arcaico (ca. del $9000 \mathrm{AC}$ hasta el 1000/700 AC). Durante el Arcaico, las poblaciones humanas vivían en grupos poco numerosos y tenían un patrón de comportamiento marcadamente nómade, conforme a una economía basada en la caza y recolección (Aschero 2000).

Esta primera etapa es luego seguida por otra denominada Formativo, que suele ser subdividida en Formativo 
Inferior (700 AC - 700 DC) y Formativo Superior (700 DC - 1000 DC). Se considera a este lapso del desarrollo sociocultural como transicional entre el modo de vida cazador-recolector y el agrícola-pastoril. En el mismo comienzan a conformarse las primeras sociedades de cultivadores y pastores sedentarios, mediando un sedentarismo de características dinámicas, con organización política simple, escasa estratificación social y relativamente baja complejidad desde el punto de vista de las jerarquizaciones (González y Pérez 1972). Estas sociedades habrían explotado una diversa gama de recursos por medio de una variedad de estrategias (economía mixta agroganadera con énfasis en pastoreo de llama, caza de camélidos silvestres y recolección estacional de frutos) y habrían mantenido una importante dinámica intra $e$ interregional por medio del establecimiento de cadenas de relaciones económicas y biosociales (Albeck 2000). Hacia finales de esta etapa, la producción agropecuaria habría alcanzado nuevos niveles de explotación, donde la incorporación de infraestructuras de regadío habría permitido un incremento en la productividad (Tarragó 2000) y un subsecuente aumento de la densidad poblacional, los cuales a su vez habrían generado la necesidad de anexar y controlar nuevos territorios. Esta situación, entre otras, bien podría haber desembocado en la ocurrencia de luchas y enfrentamientos caracterizados por niveles notables de violencia armada (Ottonello y Lorandi 1987).

Posteriormente, a partir del periodo de Desarrollos Regionales (1000 DC - 1400 DC), a juzgar por la expresión arquitectónica de grandes poblados de características semiurbanas, entre otros indicadores, se ha postulado la existencia de un gran cambio caracterizado por una tendencia hacia una mayor densidad poblacional, propiciado esto por el aumento y/o concentración de poblaciones hasta entonces territorialmente dispersas (Kolata 1993; Nielsen 1996). Durante los Desarrollos Regionales se habría dado un notable florecimiento regional, potenciado por el afianzamiento de una economía de producción agrícola y pastoril y por el intercambio entre regiones. La intensificación en las actividades agrícolas con fines de complementación de excedentes llevó a que los espacios productivos se volviesen más restrictos y más disputados, motivo por el cual fueron construidas en toda la región centro sur andina estructuras defensivas denominadas pukaras (Núñez y Dillehay 1995). De esta forma, surgie- ron sociedades organizadas en nucleamientos residenciales de tipo conglomerado semiurbano, preferencialmente emplazados sobre lugares elevados, naturalmente protegidos. Esta situación sería el producto de fenómenos de competencia territorial tanto internos como externos y del posible surgimiento de tensiones sociales y relaciones demográficas complejas, de índoles diversas (Ottonello y Lorandi 1987; Nielsen 1996, 2001; Tarragó 2000).

Finalmente, en los últimos momentos de vida exclusivamente aborigen (ca. $1400 \mathrm{DC}$ ), tuvo lugar un proceso de expansión imperial altoandina que terminó por incorporar efectivamente al NOA dentro de los dominios de la última expansión incaica. Así, el NOA pasó a formar parte del territorio inca denominado Kollasuyu y su función principal parece haber sido la explotación de riquezas mineras y de productos agrícolas; el tributo laboral y también proporcionar manufacturas de cerámica, textilería y trabajo lapidario (González 1978; Raffino 1981; Williams 2000; González y Tarragó 2004). El estado imperial incaico ejerció una poderosa influencia en las sociedades nativas del NOA y seguramente también generó una variedad de situaciones de tensión y conflicto regional en las diferentes poblaciones de los territorios anexados. Aunque esta situación debió cambiar notablemente ciertos aspectos materiales y sociopolíticos vigentes en la región, el núcleo cultural fundamental y la lengua se mantuvieron sin acusar mayores cambios hasta la penetración y dominación final por parte de contingentes militares y religiosos europeos, tras los cuales se establecería la institución de la Colonia. (Mendonça et al. 1997; Tarragó 2000).

La dominación incaica se encontraba en pleno proceso de afianzamiento en el momento en que se produce el arribo de los contingentes europeos y el posterior colapso de las sociedades nativas (González y Pérez 1972; Ottonello y Lorandi 1987). Debido a que las realidades regionales, la geografía y la índole de las capacidades de resistencia de las poblaciones nativas a nivel local y regional difirieron de manera notable, Mendonça et al. (2013) han propuesto subdividir al denominado periodo Hispano-Indígena estableciendo una división dinámica dentro del mismo:

Hispano-Indígena I, etapa caracterizada por un alto grado de conservación de la integridad sociocultural nativa. Si bien las poblaciones locales pudieron haber tenido 
acceso a algunos productos de origen europeo, la presencia de los mismos en los contextos funerarios no refleja la existencia de un contacto físico y/o biológico efectivo con los invasores, sino más bien una introducción y difusión facilitada y/o mediada por estructuras aborígenes preexistentes de circulación e intercambio.

Hispano-Indígena II, donde sí se verifica el contacto y el impacto violento signado por los sucesivos intentos de conquista y penetración territorial española. Esta segunda etapa culminará con la efectiva imposición institucional, tanto armada como religiosa, que condujo al quebrantamiento y a la desarticulación definitiva de las creencias, valores e instituciones de las sociedades nativas (Mendonça et al. 1997). Es recién durante esta etapa donde se habrían llevado a cabo las diferentes formas de violencia e imposición contrarreformista que caracterizaron el accionar de la conquista y colonización española.

En esta breve síntesis de la evolución social y cultural de las sociedades del NOA es posible proponer la existencia de una variedad de escenarios eventualmente propicios para la ocurrencia de episodios de violencia interpersonal mediados por enfrentamientos de índole grupal, los cuales pudieron obedecer a causales de naturaleza tanto endógena como exógena. En estos escenarios de economías de subsistencia cambiantes, de dinámica interacción social, cultural y demográfica y donde las tensiones y luchas por el control de territorios y recursos seguramente tuvieron lugar, proponemos describir, analizar e interpretar una serie de hallazgos de claros indicadores de situaciones de violencia y/o tensión social.

\section{* Materiales y Métodos}

El material óseo humano objeto de este estudio corresponde al obtenido durante distintas excavaciones realizadas en sitios con entierros del NOA. Los materiales de Yacoraite fueron recuperados durante los trabajos arqueológicos realizados por el Dr. Pedro Krapovickas entre los años 1960 y 1970, mientras que los cuatro conjuntos restantes (i. e.; Mulqui, Barrio Corrales, La Falda y Rincón Chico 21) fueron recuperados en excavaciones sistemáticas llevadas a cabo bajo la dirección de dos de los autores (OJM y MAB). Se trata de cuatro conjuntos provenientes de cuatro sitios de Quebrada de Humahuaca (Jujuy) y uno del valle de Santa María (Catamarca)
(Figura 1), los cuales se caracterizan brevemente a continuación:

Sitio Mulqui (Sj Til 20): Sitio hallado en el tramo medio de la Quebrada de Humahuaca, dentro del ejido urbano de la actual localidad de Tilcara, del cual se recuperó un conjunto de 16 individuos (tres inmaduros y 13 maduros). Las asociaciones culturales de los materiales excavados y los fechados radiocarbónicos permitieron asignarlos a momentos finales del Formativo Inferior $(575-680 \mathrm{cal}$ DC) (Mendonça et al. 1991).

Barrio Corrales (Sj Til 1): Conjunto habitacional localizado en el flanco suroeste del pukara de Tilcara. Durante las excavaciones fueron recuperados 23 individuos (13 inmaduros y 10 maduros). Fechados radiométricos y asociaciones culturales permitieron asignar a estos hallazgos a los periodos de Desarrollos Regionales e Inca (Otero 2013).

La Falda (Sj Til 43): Sitio con sepulturas individuales y dobles también localizado dentro del ejido urbano de Tilcara. Este cementerio habría estado segregado de cualquier otro tipo de ocupación humana durante el periodo en el cual fue utilizado. La importancia del sitio reside en que se trata de un sector de inhumaciones correspondientes al periodo Hispano-Indígena I, que incluye tanto evidencia cultural con influencia incaica como también indicios del contacto inicial con europeos (Mendonça et al. 1997; Bordach 2006). Se recuperaron 34 individuos, de los cuales 25 son incluidos en este trabajo.

Pukara de Yacoraite: Poblado fortificado localizado en el tramo medio de la Quebrada de Humahuaca, sobre la margen derecha del río Grande, entre la desembocadura del río Yacoraite y el arroyo Chucalezna (Krapovickas 1969). En este poblado prehistórico Pedro Krapovickas recuperó un conjunto de esqueletos de dos recintos situados en el sector oriental de la parte más alta del pukara. El conjunto resultó estar compuesto por 48 individuos, de los cuales 25 corresponden al rango de edad adolescente/ adulto. Yacoraite sería un poblado cuya vida activa habría abarcado los periodos de Desarrollos Regionales e Inca (Krapovickas 1973, 1981-1982).

Rincón Chico 21 (SSMa RCh 21): Cementerio localizado dentro de la gran localidad arqueológica de Rincón 


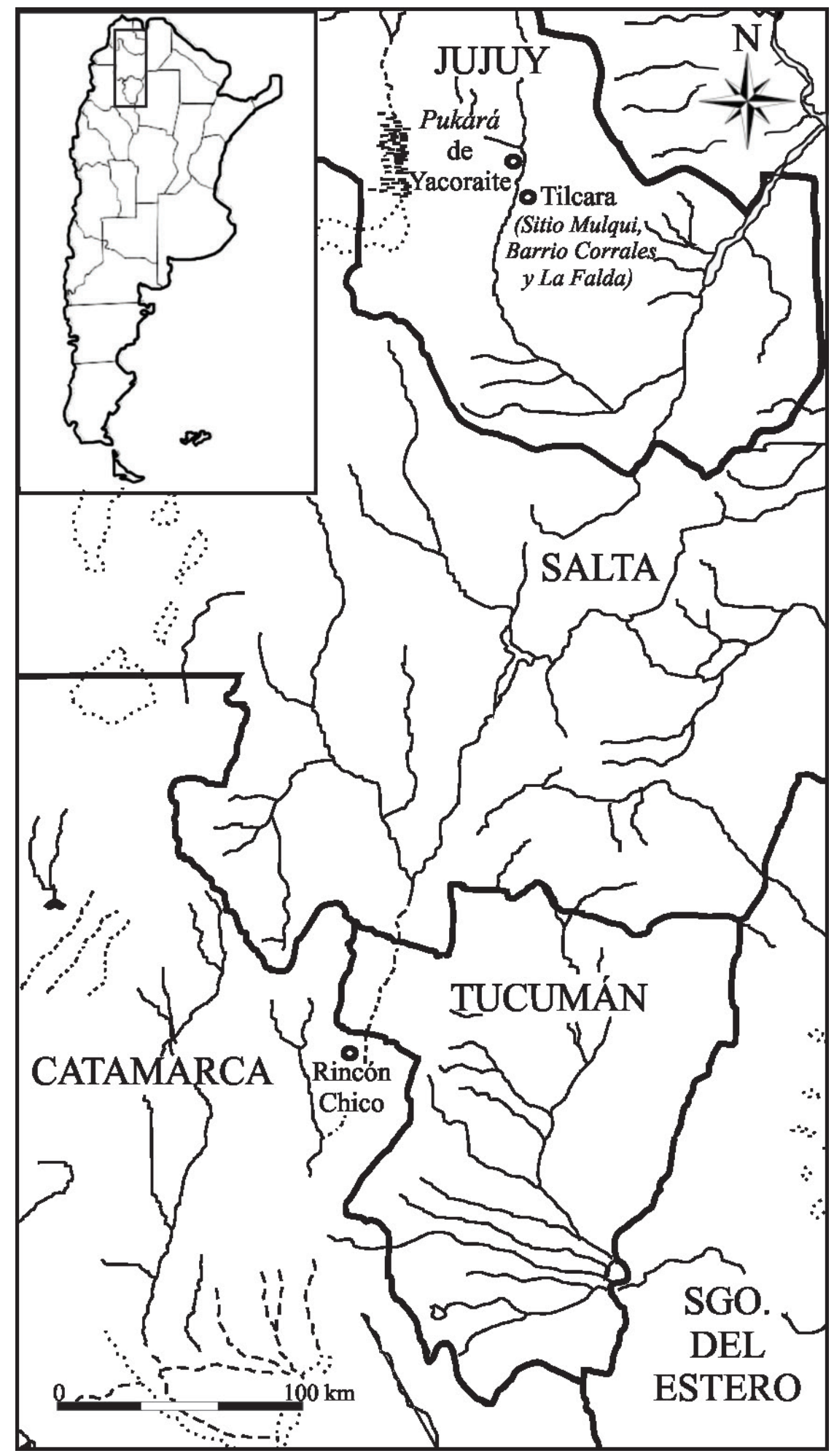

Figura 1. Mapa con la localización de los sitios incluidos en este trabajo. 
Chico, en el sector medio del valle de Santa María, provincia de Catamarca. Se ha recuperado hasta el momento un total de 76 individuos, entre inmaduros y maduros, de los cuales 57 son incluidos en este estudio. La utilización activa de este cementerio abarca desde tiempos correspondientes a los Desarrollos Regionales, para después recibir influencia del Tawantinsuyu y, finalmente, presentar indicadores culturales correspondientes a la presencia europea (Mendonça et al. 2003). Se consideran en este estudio 47 individuos culturalmente asignables a los Desarrollos Regionales / Inca, mientras que 10 individuos fueron asignados al periodo Hispano-Indígena I.

Debido a la larga secuencia ocupacional de los pukaras de Tilcara y Yacoraite, junto con las asociaciones contextuales de algunos de los rasgos del cementerio de RCh 21 (i. e.; la cámara 15), los autores han decidido unificar los periodos de Desarrollos Regionales e Inca a fin de evitar la ocurrencia de eventuales desacuerdos en la correcta asignación cronológica de los materiales estudiados.

Del total de 197 individuos proporcionados por los cinco sitios, fueron objeto de análisis 130, los cuales estaban constituidos tanto por sus esqueletos craneanos como post-craneanos. Con el fin de asegurar una mejor comparabilidad entre los distintos conjuntos, y siguiendo los lineamientos de Milner et al. (1991), Jurmain et al. (2009) y Murphy et al. (2010), este trabajo se focaliza en lesiones traumáticas atribuibles a violencia observadas en individuos con una edad al momento de la muerte mayor o igual a los 15 años $(n=130)$. En la Tabla 1 se presenta el número de individuos analizados por sitio y la asignación cronológica para cada sitio. La determinación de edad y sexo se realizó teniendo en cuenta aspectos métricos y morfológicos convencionalmente establecidos para cráneo y post-cráneo (Buikstra y Ubelaker 1994).

Para el análisis de los traumas atribuibles a eventos de violencia, la metodología empleada consistió en la observación, descripción y registro de las lesiones traumáticas presentes en cada conjunto esquelético individual. Cada uno de los elementos del esqueleto axial y apendicular fue examinado a fin de detectar la presencia de traumas posiblemente provocados por objetos punzo-penetrantes o romos y/o contundentes. Solamente fueron consideradas aquellas lesiones atribuidas a traumas directos. De este modo, se registraron fracturas penetrantes, lineales, en depresión y fracturas faciales en cráneos y mandíbulas (Lovell 1997; Torres-Rouff y Costa Junqueira 2006), mientras que para el resto del esqueleto post-craneano se consideraron como representativas de violencia interpersonal únicamente a las fracturas penetrantes (Merbs 1989; Lovell 1997). El registro de las lesiones traumáticas fue realizado teniendo en cuenta la siguiente información: tipo de hueso, lateralidad, dimensiones ectocraneales y forma y grado de compromiso endocraneal (en

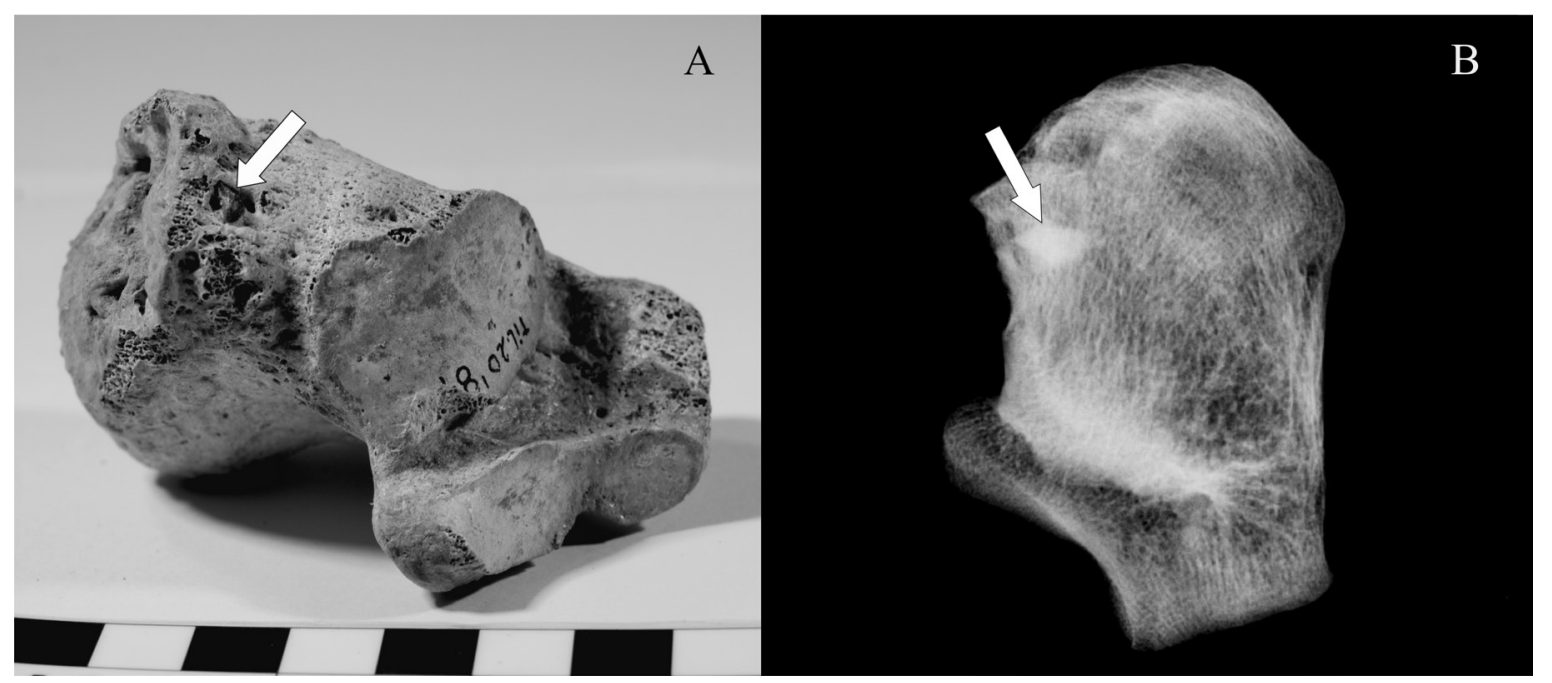

Figura 2. Calcáneo izquierdo del individuo to del sitio Mulqui. A: Vista superior donde se indica la localización del fragmento de proyectil (flecha blanca). B: Radiografía (norma superior) donde se puede observar el fragmento de proyectil lítico incrustado en el hueso (flecha blanca). 

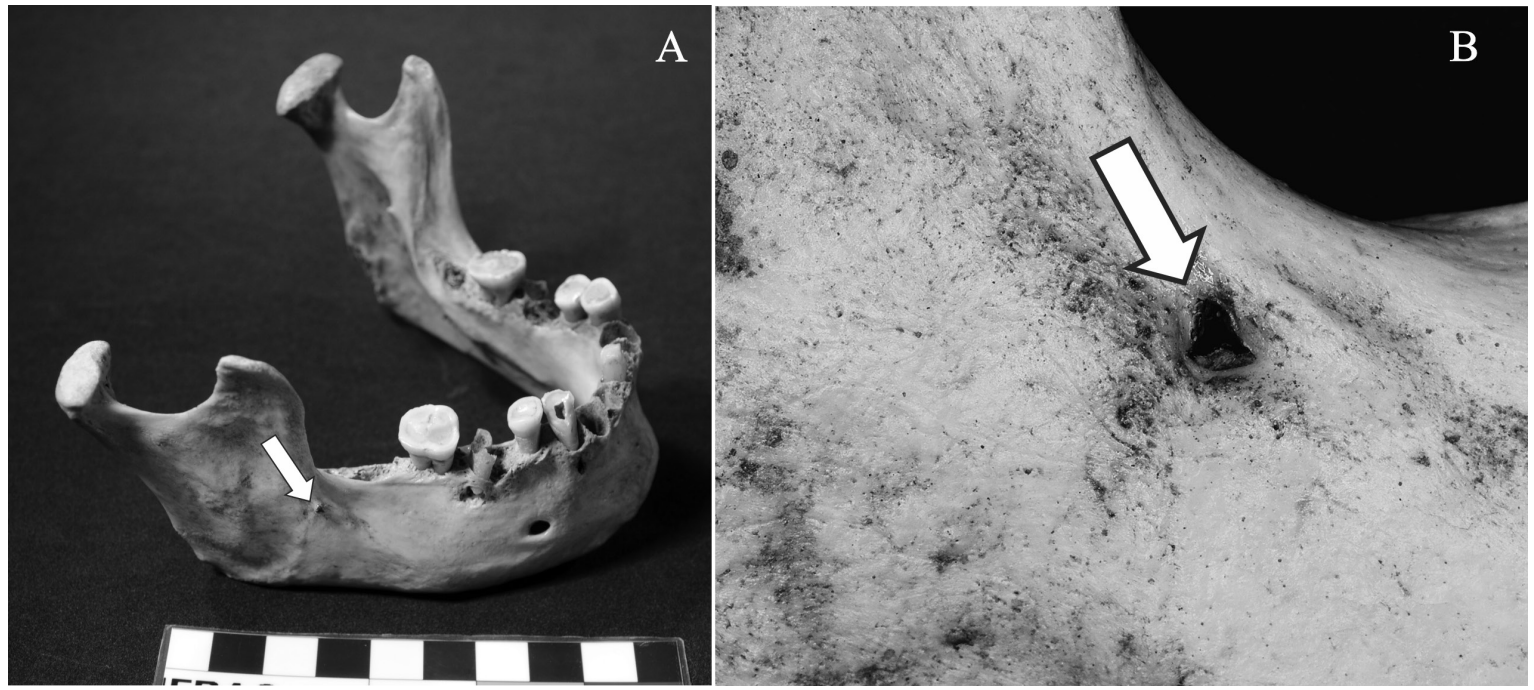

Figura 3. Mandíbula del individuo 20 del pukara de Yacoraite. A: Vista general del elemento donde se puede observar la localización del fragmento de proyectil (flecha blanca). B: Detalle donde se aprecia como el fragmento de proyectil lítico ha quedado casi totalmente recubierto por la acción reparadora del tejido óseo (flecha blanca).
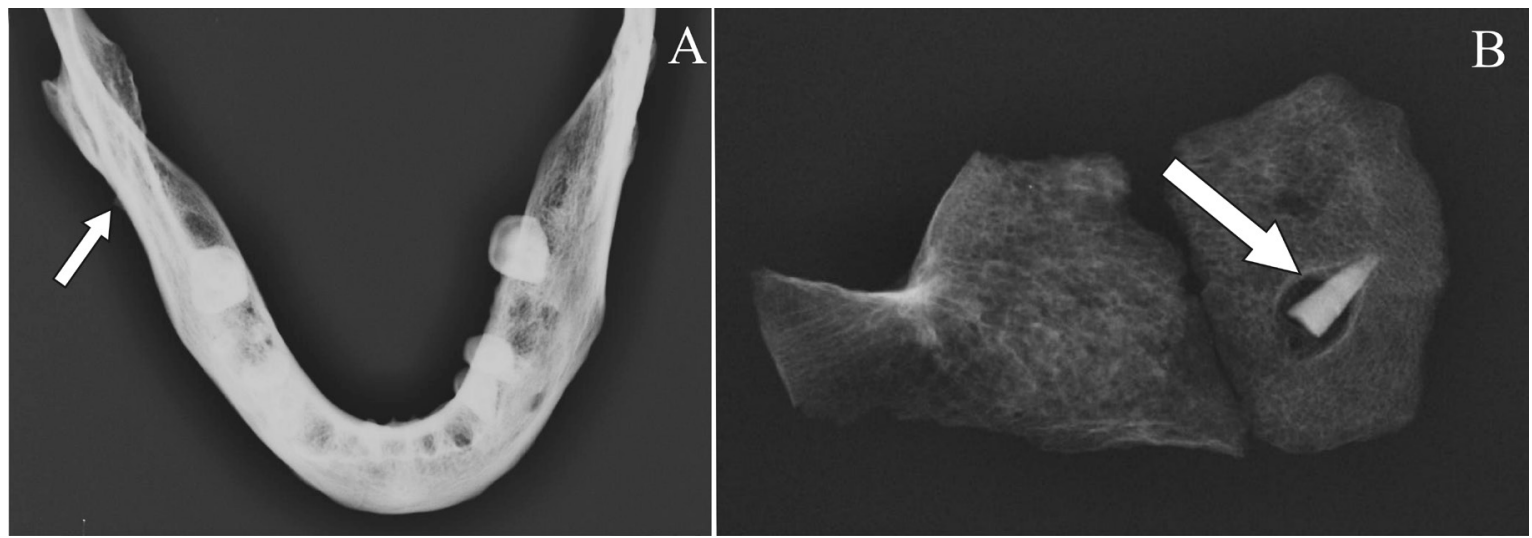

Figura 4. Imágenes radiográficas de lesiones. A: Norma superior de mandíbula del individuo 20 del pukara de Yacoraite, donde se puede apreciar el fragmento de proyectil incrustado en el hueso (flecha blanca). B. Norma lateral del calcáneo izquierdo del individuo "Z" de la cámara 8 del cementerio de Rincón Chico 21, donde claramente se observa el ápice de un proyectil lítico alojado en el hueso

(flecha blanca).

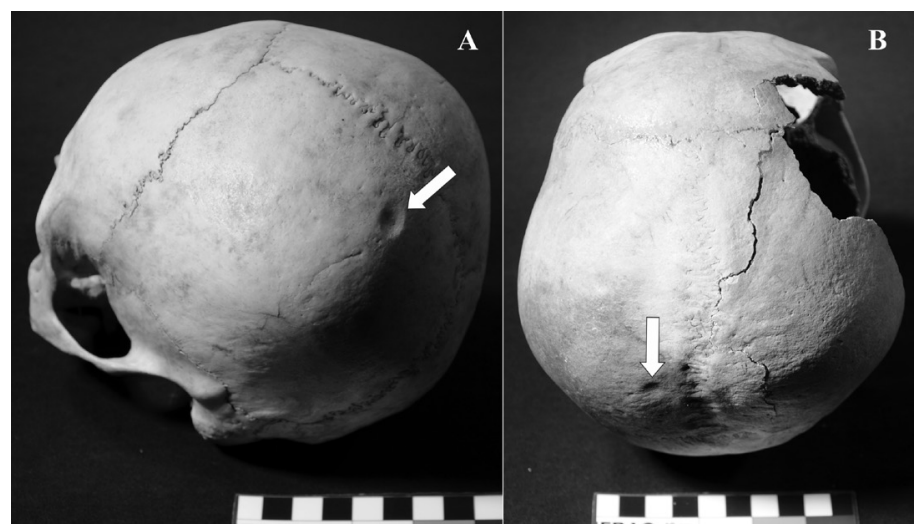

Figura 5. Lesiones halladas en cráneos del cementerio de La Falda. A: Fractura en depresión localizada en el parietal izquierdo del cráneo del individuo $\mathrm{R}_{3}$ (flecha blanca). B: Vista superior del cráneo del individuo R22 E\#7, donde se puede apreciar la fractura en depresión localizada en la región obélica izquierda (flecha blanca). 

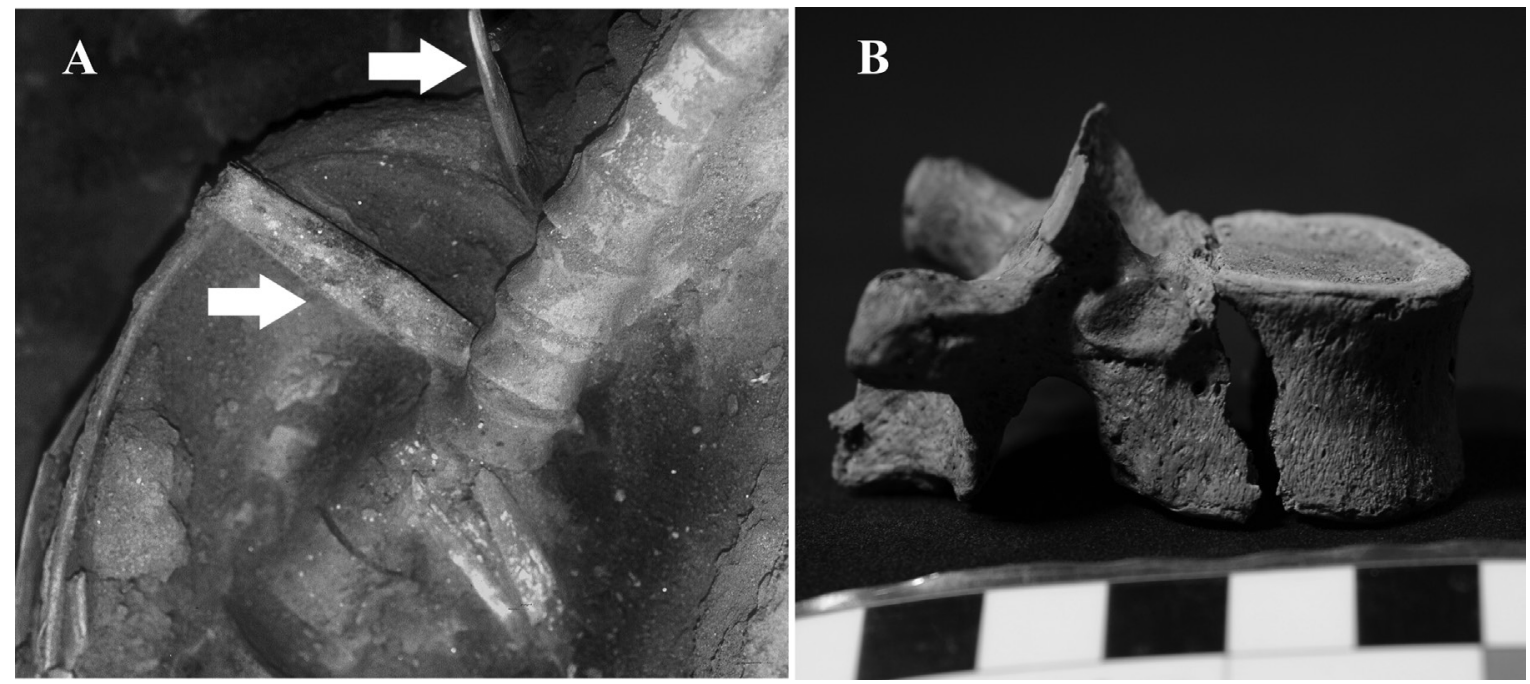

Figura 6. Individuo I de la cámara 13 del cementerio de Rincón Chico 21. A: Fotografía in situ donde se observan dos puntas de flecha impactando sobre distintos elementos de la columna vertebral. La flecha blanca superior señala la punta de proyectil hallada entre las articulaciones costovertebrales derechas de las vértebras dorsales octava y novena, mientras que la flecha blanca inferior señala la punta que impactó en el cuerpo de la décima vértebra torácica. B: Vista lateral derecha del cuerpo de la décima vértebra dorsal donde se aprecia la lesión causada por el impacto de la punta de proyectil.

cráneo), posición en el elemento óseo (proximal, medial o distal en el caso de los huesos largos) y configuración de la fractura (longitud del hueso fracturado y ángulo de la línea de fractura) (Lovell 1997). El reconocimiento de las heridas antemortem respecto de las perimortem estuvo dado por la existencia o no de remodelado óseo en el lugar del impacto, resultando tal remodelado en la formación de un callo cicatricial o, en su defecto, por la presencia de bordes romos (Buikstra y Ubelaker 1994; Sauer 1998; Walker 2001). La observación de las lesiones fue reali- zada mediante inspección ocular simple y subsecuentemente mediante el empleo de un magnificador óptico con luz adosada y una lupa binocular. También se obtuvieron placas radiográficas de aquellos elementos que manifestaron la presencia de fracturas penetrantes. Para la medición de las dimensiones de las lesiones se utilizó un compás de ramas rectas.

Los eventos de trauma óseo también fueron analizados, comparados e interpretados en el contexto de

\begin{tabular}{|c|c|c|c|}
\hline $\begin{array}{l}\text { Asignación } \\
\text { Cronológica }\end{array}$ & Conjunto Osteológico & Número de individuos ( 815 años) & Fechados radiocarbónicos cal. 2 sigma $\mathrm{AD}$ \\
\hline FORMATIVO & $\begin{array}{l}\text { Sitio Mulqui } \\
\text { (SJTil 20) }\end{array}$ & 13 & Beta-132947 (hueso humano): 565-689 \\
\hline \multirow{3}{*}{$\begin{array}{l}\text { DESARROLLOS } \\
\text { REGIONALES / INCA }\end{array}$} & Barrio Corrales (SJTil 1 ) & 10 & $\begin{array}{l}\text { LP - } 247 \text { (fogón): 1205-1304 } \\
\text { AA-88.340 (carbón): 1397-1484 }\end{array}$ \\
\hline & Yacoraite & 25 & - \\
\hline & $\begin{array}{l}\text { Rincón Chico } 21 \\
\text { (RCh 21) }\end{array}$ & 47 & $\begin{array}{l}\text { Beta-181724 (madera): } 1390-1513 \\
\text { Beta-186150 (carbón): } 1383-1463\end{array}$ \\
\hline \multirow{2}{*}{$\begin{array}{l}\text { HISPANO-INDÍGENA } \\
\text { INICIAL }\end{array}$} & $\begin{array}{l}\text { Cementerio de La Falda } \\
\text { (SJTil 43) }\end{array}$ & 25 & $\begin{array}{l}\text { Beta-153720 (lino): 1441-1635 } \\
\text { Beta-153721 (terciopelo): 1446-1635 }\end{array}$ \\
\hline & $\begin{array}{l}\text { Rincón Chico } 21 \\
\text { (RCh 21) }\end{array}$ & 10 & - \\
\hline
\end{tabular}

Tabla 1. Asignación cronológica, número de individuos y dataciones cronológicas por fechados radiocarbónicos correspondientes a cada uno de los conjuntos osteológicos contemplados en este trabajo. 
Violencia Interpersonal en el Noroeste Argentino Prehistórico:

EXPRESIONES REgIONALES, SOCIOCULTURALES y Cronológicas

\begin{tabular}{|c|c|c|c|c|c|c|}
\hline Desarrollo sociocultural & Sitio & Rasgo & Sexo & $\begin{array}{l}\text { Edad } \\
\text { (años) }\end{array}$ & $\begin{array}{l}\text { Elemento } \\
\text { anatómico } \\
\text { afectado }\end{array}$ & Tipo de trauma \\
\hline FORMATIVO & $\begin{array}{l}\text { Sitio Mulqui } \\
\text { (SJ Til 2O) }\end{array}$ & C-IV & M & $33-45$ & Calcáneo izquierdo & $\begin{array}{l}\text { Fractura penetrante (punta obsidiana) (Figuras } 2 \text { A } \\
\text { y } 2 \text { B). Presencia de actividad cicatricial }\end{array}$ \\
\hline \multirow{7}{*}{$\begin{array}{l}\text { D E S A R R O L L O S } \\
\text { REGIONALES / INCA }\end{array}$} & \multirow{2}{*}{ Yacoraite } & $\mathrm{C}-\mathrm{H}$ & M & $35-40$ & $\begin{array}{l}\text { Cráneo } \\
\text { (hemifrontal } \\
\text { izquierdo) }\end{array}$ & $\begin{array}{l}\text { Fractura en depresión semicircular de } 7 \text { × } 4 \mathrm{~mm} \text {. } \\
\text { Presencia de remodelado óseo }\end{array}$ \\
\hline & & $\mathrm{C}-\mathrm{H}$ & M & $45-50$ & $\begin{array}{l}\text { Mandíbula (rama } \\
\text { mandibular } \\
\text { derecha) }\end{array}$ & $\begin{array}{l}\text { Fractura penetrante (punta obsidiana) (Figuras } 3 \text { A } \\
\text { y } 4 \text { A). Presencia de actividad cicatricial (Figura } 3 \text { B) }\end{array}$ \\
\hline & \multirow{5}{*}{$\begin{array}{l}\text { Rincón Chico } \\
21 \quad(S S M a \\
\text { RCh 21) }\end{array}$} & $C-1$ & M & Adulto & $\begin{array}{l}\text { Cráneo } \\
\text { (hemifrontal } \\
\text { derecho) }\end{array}$ & $\begin{array}{l}\text { Fractura en depresión semicircular de aprox. } 11 \mathrm{~mm} \\
\text { de diámetro. Presencia de remodelado óseo }\end{array}$ \\
\hline & & C-8 & M & $39-44$ & Calcáneo izquierdo & $\begin{array}{l}\text { Fractura penetrante (punta obsidiana). Fragmento } \\
\text { de proyectil dentro de cavidad lítica oval de } 7 \times 10 \\
\mathrm{~mm} \text { muy probablemente generada por infección } \\
\text { post traumática (Figura } 4 \text { B) }\end{array}$ \\
\hline & & $\mathrm{C}-11$ & $\mathrm{~F}$ & $27-30$ & $\begin{array}{l}\text { Cráneo } \\
\text { (hemifrontal } \\
\text { derecho) }\end{array}$ & $\begin{array}{l}\text { Fracturas en depresión (2). Una circular de } 5 \mathrm{~mm} \\
\text { de diámetro; otra elipsoidal de } 9 \text { x } 12 \mathrm{~mm} \text {. Ambas } \\
\text { evidencian actividad reparadora }\end{array}$ \\
\hline & & $C-15$ & M & Adulto & $\begin{array}{l}\text { Diáfisis húmero } \\
\text { derecho (tercio } \\
\text { medial) }\end{array}$ & $\begin{array}{l}\text { Fractura penetrante (punta obsidiana). Presencia } \\
\text { de exostosis rodeando lesión (probable miositis } \\
\text { osificante post traumática) }\end{array}$ \\
\hline & & ED II & $\mathrm{F}$ & $13 \cdot 5-15 \cdot 5$ & $\begin{array}{l}\text { Cráneo (parietal } \\
\text { izquierdo) }\end{array}$ & $\begin{array}{l}\text { Fractura en depresión elipsoidal de } 7 \times 11 \mathrm{~mm} \text {. } \\
\text { Presencia de remodelado óseo }\end{array}$ \\
\hline \multirow{6}{*}{$\begin{array}{l}\text { HISPANO-INDÍGENA } \\
\text { INICIAL }\end{array}$} & \multirow{4}{*}{$\begin{array}{l}\text { La Falda } \\
(\text { SJ Til 43) }\end{array}$} & $\mathrm{R}_{3}$ & $\mathrm{~F}$ & $>50$ & $\begin{array}{l}\text { C r á n e o } \\
\text { (hem if rontal } \\
\text { derecho y parietal } \\
\text { izquierdo) }\end{array}$ & $\begin{array}{l}\text { Fracturas en depresión (2) elipsoidales. La del } \\
\text { frontal aprox. } 12 \mathrm{~mm} \text { de diámetro; la del parietal } 10 \\
\mathrm{~mm} \text { de diámetro (Figura } 5 \mathrm{~A} \text { ). Ambas evidencian } \\
\text { actividad reparadora }\end{array}$ \\
\hline & & $\mathrm{R}_{13}$ & M & $20-21$ & $\begin{array}{l}\text { C r á n e o } \\
\text { (hem if ro n t a l } \\
\text { izquierdo) }\end{array}$ & $\begin{array}{l}\text { Fractura en depresión semilunar de } 9 \mathrm{~mm} \text { de } \\
\text { ancho. Presencia de remodelado óseo }\end{array}$ \\
\hline & & $\mathrm{R}_{17}$ & M & $18-19$ & $\begin{array}{l}\text { C r á n e o } \\
\text { (hemifrontal } \\
\text { derecho) }\end{array}$ & $\begin{array}{l}\text { Fractura en depresión circular de aprox. } 8 \mathrm{~mm} \text { de } \\
\text { diámetro. Presencia de remodelado óseo }\end{array}$ \\
\hline & & $\mathrm{R} 22$ & M & $40-45$ & $\begin{array}{l}\text { Cráneo (parietal } \\
\text { izquierdo) }\end{array}$ & $\begin{array}{l}\text { Fracturas en depresión (3). Dos de } 5 \mathrm{~mm} \text { de } \\
\text { diámetro y una de } 4 \mathrm{~mm} \text { diámetro. Presencia de } \\
\text { remodelado óseo (Figura } 5 \mathrm{~B} \text { ) }\end{array}$ \\
\hline & \multirow[t]{2}{*}{$\begin{array}{l}\text { Rincón Chico } \\
21 \quad(\text { SSMa } \\
\text { RCh 21) }\end{array}$} & $\mathrm{C}_{13}$ & M & $22-24$ & Columna vertebral & $\begin{array}{l}\text { Fracturas penetrantes (3) provocadas por puntas } \\
\text { elaboradas sobre hueso. Una impactó cuerpos } \\
\text { vertebrales de } \mathrm{C} \text { y } \mathrm{C}_{7} \text {; otra penetró cuerpo de Tio } \\
\text { (Figuras } 6 \mathrm{~A} \text { y } 6 \mathrm{~B} \text { ). Otras } 7 \text { puntas asociadas a } \\
\text { violencia fueron encontradas in situ. Ausencia de } \\
\text { respuesta ósea }\end{array}$ \\
\hline & & $\mathrm{C}_{13}$ & M & $13-16$ & Columna vertebral & $\begin{array}{l}\text { Impacto de punta de proyectil de hueso a nivel } \\
\text { de articulación costovertebral izquierda de } \mathrm{T} 5 \mathrm{y} \\
\text { presencia de otra a nivel de cavidad abdominal }\end{array}$ \\
\hline
\end{tabular}

Tabla 2. Síntesis de casos de trauma atribuidos a violencia interpersonal para cada uno de los sitios considerados. 
Mario A. Arrieta, lila Bernardi, María de la Asunción Bordach y Osvaldo J. Mendonça

\begin{tabular}{|c|c|c|c|c|c|c|c|}
\hline \multirow{2}{*}{ Desarrollo sociocultural } & \multirow{2}{*}{ Sitio } & \multicolumn{2}{|c|}{ Masculinos } & \multicolumn{2}{|c|}{ Femeninos } & \multicolumn{2}{|l|}{ Total } \\
\hline & & $\mathbf{n} / \mathbf{N}$ & $\%$ & $\mathbf{n} / \mathbf{N}$ & $\%$ & $\mathbf{n} / \mathbf{N}^{\star}$ & $\%$ \\
\hline FORMATIVO & Sitio Mulqui & $1 / 5$ & 20 & $\mathrm{o} / 6$ & o & $1 / 13$ & 7.69 \\
\hline \multicolumn{2}{|l|}{ Total } & $1 / 5$ & 20 & $0 / 6$ & o & $1 / 13$ & 7.69 \\
\hline \multirow{3}{*}{$\begin{array}{l}\text { DESARROLLOS REGIONALES } \\
\text { INCA }\end{array}$} & Barrio Corrales & $0 / 5$ & o & $0 / 5$ & o & $\mathrm{o} / 10$ & o \\
\hline & Yacoraite & $2 / 13$ & 15.38 & $0 / 12$ & o & $2 / 25$ & 8 \\
\hline & Rincón Chico 21 & $3 / 22$ & 13.64 & $2 / 24$ & 8.33 & $5 / 47$ & 10.64 \\
\hline \multicolumn{2}{|l|}{ Total } & $5 / 40$ & 12.5 & $2 / 41$ & 4.88 & $7 / 82$ & 8.54 \\
\hline \multirow{2}{*}{ HISPANO-INDÍGENA INICIAL } & La Falda & $3 / 10$ & 30 & $1 / 15$ & 6.67 & $4 / 25$ & 16 \\
\hline & Rincón Chico 21 & $2 / 6$ & 33.33 & $0 / 4$ & $\circ$ & $2 / 10$ & 20 \\
\hline \multicolumn{2}{|l|}{ Total } & $5 / 16$ & 31.25 & $1 / 19$ & 5.26 & $6 / 35$ & 17.14 \\
\hline
\end{tabular}

Tabla 3. Distribución por sexo, sitio y etapa de desarrollo sociocultural de individuos con lesiones atribuibles a violencia.

Las frecuencias se muestran por $\mathrm{n} / \mathrm{N}$ (nro. de individuos afectados sobre el total de individuos).

*En la columna del total de individuos por sitio, además de los masculinos y femeninos, también fueron incluidos aquellos individuos de sexo indeterminado.

información teórica y documental global que los contiene, particularmente en lo que hace a su marco socioeconómico-cultural y cronológico. Finalmente, para comparar las frecuencias de individuos afectados por lesiones atribuibles a violencia entre los distintos periodos se aplicó la prueba de Chi-cuadrado con un nivel de significación menor a 0.05 .

\section{$*$ Resultados}

Una síntesis de las lesiones atribuibles a violencia observadas en cada uno de los individuos de los sitios estudiados, atendiendo particularmente a las asignaciones cronológicas de cada uno de los rasgos donde se encontraban incluidos, es presentada en la Tabla 2.

En la Tabla 3 se puede observar que la prevalencia de individuos afectados por lesiones traumáticas atribuibles a violencia fue mayor para el periodo Hispano-Indígena I $(6 / 35,17.14 \%)$. Para este periodo, la frecuencia de individuos de sexo masculino afectados es similar en los dos sitios considerados (aprox. $30 \%$ ). Estas frecuencias fueron claramente mayores a las de masculinos afectados para los otros dos periodos considerados. Para los Desarrollos Regionales / Inca, el porcentaje de individuos afectados fue del $8.54 \%$ (7/82), y aquí también se ob- serva una mayor frecuencia de traumas en masculinos, aunque dos individuos de sexo femenino provenientes de Rincón Chico 21 manifestaron fracturas en depresión en el cráneo. Para el sitio Barrio Corrales (Desarrollos Regionales / Inca) no se registró evidencia alguna de violencia y solamente un individuo del Formativo Inferior $(1 / 13,7.69 \%)$ manifestó una lesión asociada a violencia. Finalmente, el conjunto osteológico de Rincón Chico 21 asignado al periodo Hispano-Indígena inicial sería el más afectado por trauma relacionado con violencia en este estudio (Tabla 3).

Si bien se observan diferencias entre la prevalencia de individuos afectados del periodo Hispano-Indígena I y las de las otras dos etapas consideradas, los resultados de los tests Chi-Cuadrado aplicados no permitieron validar que tales diferencias fueran estadísticamente significativas (Formativo Inferior vs. Desarrollos Regionales / Inca: $\mathrm{X}_{2}=0.01, \mathrm{P}=0.92$; Formativo Inferior vs. Hispano-Indígena I: $\mathrm{X} 2=0.68, \mathrm{P}=0.41$; Desarrollos Regionales $/$ Inca vs. Hispano-Indígena I: $\mathrm{X}_{2}=1.84, \mathrm{P}=0.18$ ). Tampoco se observaron diferencias estadísticamente significativas entre periodos cuando se consideraron únicamente aquellos individuos que manifestaron fracturas penetrantes provocadas por puntas de proyectil (Formativo Inferior vs. Desarrollos Regionales / Inca: $\mathrm{X} 2=0.45, \mathrm{P}=0.50$; 
Formativo Inferior vs. Hispano-Indígena I: $\mathrm{X}_{2}=0.06$, $\mathrm{P}=0.80$; Desarrollos Regionales / Inca vs. Hispano-Indígena I: $\mathrm{X}_{2}=0.25, \mathrm{P}=0.61$ ). En cuanto a la prevalencia de lesiones asociadas a violencia según el sexo de los individuos, se observaron diferencias significativas cuando se compararon el total de hombres y mujeres incluidos en este estudio $\left(\mathrm{X}_{2}=5.88, \mathrm{P}=0.02\right)$ y en el periodo Hispano-Indígena inicial $\left(\mathrm{X}_{2}=4.13, \mathrm{P}=0.04\right)$.

\section{* Discusión}

Si bien se observan diferencias en las prevalencias de individuos afectados por lesiones traumáticas posiblemente causadas por eventos de violencia, tal como fuera planteado en la hipótesis inicial, el tratamiento estadístico realizado no permitió confirmar la existencia de un aumento considerable de situaciones de violencia en ninguno de los momentos del desarrollo sociocultural representados por el conjunto de esqueletos aquí analizados. Esta circunstancia podría estar relacionada con las limitaciones impuestas por el número de individuos que componen el conjunto total estudiado. No obstante los autores estiman conveniente resaltar el carácter excepcional en términos de integridad del conjunto de esqueletos (cráneo y postcráneo) que ha sido estudiado en este trabajo.

En síntesis, las únicas afirmaciones que nos permiten realizar los resultados proporcionados por los materiales considerados en este estudio es que los eventos de violencia interpersonal estuvieron presentes y atravesaron a toda la secuencia sociocultural comprendida por esta experiencia, y donde los hombres se habrían visto mayormente comprometidos en la participación de tales eventos. Asimismo, y a menos que se trate de un artefacto propio de la índole de los materiales por nosotros trabajados, la prevalencia de este tipo de lesiones es apenas mayor en la secuencia correspondiente a los Desarrollos Regionales / Inca respecto a lo que se verifica, por ejemplo, para el Formativo Inferior. Más aún, nuestros resultados tampoco se condicen con aquellos obtenidos en estudios trasandinos para momentos culturales cronológicamente similares, en los cuales se han observado cambios temporales en la prevalencia de indicadores óseos de violencia en otros grupos correspondientes a otras regiones del área centro-sur andina (i.e.; Atacama) (Torres-Rouff et al. 2005; Torres-Rouff y Costa Junqueira
2006). Una discusión más detallada respecto a los indicadores óseos de violencia observados en los conjuntos analizados se presenta a continuación.

\section{Indicadores de violencia en el Formativo Inferior}

La lesión observada en el calcáneo izquierdo del individuo 10 del sitio Mulqui constituye una señal inequívoca de la ocurrencia de eventos de violencia interpersonal en tiempos formativos. Si bien este único evento no habría causado per se la muerte del individuo, el hallazgo de otra punta de proyectil completa en el interior de la cavidad torácica del mismo individuo sí podría estar relacionado con la causa directa de su muerte (Mendonça et al. 1991). Asimismo, las puntas de proyectil incluidas a modo de ofrenda en dos de las tumbas excavadas en este sitio podrían estar poniendo de manifiesto por un lado la importancia social de tales elementos y su valor simbólico en tanto armas y, por otro, la existencia de individuos de esta población involucrados efectivamente en el desarrollo activo de actividades bélicas. Adicionalmente, los indicadores de violencia observados en este conjunto óseo sugieren la ocurrencia de enfrentamientos a distancia que muy probablemente podrían haberse producido entre grupos tanto locales como no locales. En cuanto a la índole de los disparadores de estos conflictos, la competencia por recursos considerados limitados o escasos parecería ser la causa más probable. Empero, lo que resulta aparente es que estos hechos de violencia, cualesquiera que hayan sido sus orígenes o disparadores, existían en la quebrada de Humahuaca, y seguramente en otras regiones colindantes, por lo menos ya desde tiempos formativos. En este sentido, cabe mencionar que evidencia de situaciones de violencia interpersonal durante el Formativo también fue registrada por González Baroni (2013), quien observó la presencia de fracturas craneanas atribuibles a situaciones de violencia en cuatro individuos del sitio PP 9 (Antofagasta de la Sierra, Catamarca), datado en ca. 1300 AP. Otros hallazgos de evidencia de violencia interpersonal para la misma franja temporal en otras áreas del centro-sur andino han sido realizados por Torres-Rouff y Costa Junqueira (2006) en el sitio Solcor 3 (10.9\% de 92 cráneos analizados) y Lessa y Mendonça de Souza (2007) en el sitio Coyo 3 (21.74\% de 46 individuos analizados), ambos sitios localizados en el oasis atacameño (Chile). Adicionalmente, Standen y Arriaza (2000) hallaron lesiones atribuibles a violencia 
en 17 cráneos (24.6\%) y en una vértebra lumbar de un conjunto osteológico de 144 esqueletos provenientes de cinco cementerios de Arica (Chile) asociados a la cultura Chinchorro (ca. $4000 \mathrm{AC}$ ). De este modo, y en base a la información proporcionada por otros estudios, la existencia de eventos de tensión y/o disrupción social en el NOA, ya desde épocas anteriores a los Desarrollos Regionales, no debería ser considerada como una situación de características excepcionales ni extraordinarias.

\section{Indicadores de violencia en los Desarrollos Regio- nales / Inca}

Las lesiones detectadas en el pukara de Yacoraite fueron producidas por traumas directos, muy probablemente vinculados con eventos de violencia interpersonal. En este sentido, la fractura registrada en el individuo 16 se corresponde con aquellas lesiones producidas por objetos en movimiento que impactan en la cabeza. Por las características de la fractura, ésta parece haber sido causada por un objeto de relativamente baja velocidad, tal como un guijarro u otra arma de extremos romos (Lovell 1997). La localización de la lesión (hemifrontal izquierdo) sugeriría el enfrentamiento cuerpo a cuerpo con un contrincante provisto con un arma tal como un bastón de madera, aunque no se puede descartar que la herida haya sido provocada por un guijarro lanzado por medio de una honda, todas ellas armas utilizadas para esta época en el sur andino (Bennett 1946; Nielsen 2009). Otra posibilidad también es la existencia de algún tipo de lucha ritual y/o simbólica entre integrantes de un mismo grupo. No obstante, no nos es posible descartar que la lesión registrada haya sido el resultado de una mera ocurrencia accidental. En cuanto a la lesión registrada en la mandíbula del individuo 20 , una fractura penetrante causada por una punta lítica de proyectil, ésta efectivamente pone de manifiesto la existencia de situaciones de tensión social vinculadas con enfrentamientos armados a distancia, que posiblemente ocurrieron entre grupos de diferentes procedencias. Adicionalmente, Krapovickas (1973:368) menciona que "... Entre los huesos del tronco de uno de los individuos estaba una punta de flecha de obsidiana..." y seguidamente afirma que "...Perteneció sin ninguna duda al arma que causó su deceso”. Según Albeck (1992), el pukara de Yacoraite, que ocupaba una posición geográfica estratégica y es considerado como un importante asentamiento nodal, habría sido el cuarto sitio más extenso de la Quebrada de Humahuaca y uno de los que habría presentado una mayor densidad ocupacional. Ante esta situación, la defensa del territorio y de las fuentes de aprovisionamiento podría muy bien haber sido un factor determinante en la generación de enfrentamientos armados.

En lo que respecta a la evidencia proporcionada por el cementerio de Rincón Chico 21, los casos de violencia correspondientes al húmero impactado hallado en la C-15 y el calcáneo del individuo "Z" de la C-8 se habrían originado, en primera instancia, como consecuencia de enfrentamientos a distancia. En ambos casos se trató de puntas de flechas elaboradas sobre obsidiana, circunstancia que pone de manifiesto la existencia de diferencias tanto de índole cronológica como cultural entre estos eventos de violencia y los registrados en la C-13, que se discutirán más adelante. El ataque sufrido por el individuo de la C-15 no fue mortal, ya que rodeando al proyectil incrustado se encontraba una masa amorfa de hueso que indica que este individuo sobrevivió el tiempo suficiente como para que el organismo reaccionara y en el sitio de la herida se formase una lesión del tipo miositis osificante traumática. En cuanto al individuo de la C-8, si bien el mismo sobrevivió al ataque, en el sitio de la lesión se había desarrollado una infección que todavía se encontraba activa al momento de su muerte. Esta situación deja abierta la posibilidad de que la causa real del deceso haya sido una secuela infecciosa disparada por el evento de violencia mencionado. Sin embargo, la notable reacción ósea al ingreso de tales agentes extraños pone en evidencia la supervivencia de los individuos que sufrieron sendos ataques. En cuanto a las lesiones observadas en los tres cráneos, dos de ellos pertenecientes a individuos de sexo femenino, éstas parecen haber sido provocadas por objetos contundentes cuyo impacto no fue suficiente como para ocasionar la muerte de los individuos. Al igual que la lesión observada en Yacoraite, estas lesiones podrían responder tanto a enfrentamientos cuerpo a cuerpo como a distancia, o a eventuales accidentes. En cuanto a la presencia de traumas atribuibles a violencia en dos individuos femeninos, éstos eventualmente podrían ser interpretados como resultado de violencia doméstica (Lessa y Mendonça de Souza 2007). Sin embargo, no se puede descartar que las mujeres hayan participado activamente en los conflictos intergrupales, tal como proponen Torres-Rouff et al. (2005). 
Como resulta aparente, las situaciones de violencia interpersonal aquí descriptas se habrían presentado tanto en poblaciones de Quebrada de Humahuaca como en sus coetáneas de los valles Calchaquíes. Si bien una consideración más prudente fue asignar los materiales provenientes de Yacoraite y RCh 21 a un periodo Desarrollos Regionales / Inca unificado, las asociaciones contextuales de las tumbas excavadas en ambos sitios sugieren fuertemente que la gran mayoría de los esqueletos analizados pertenecen a los Desarrollos Regionales antes que al periodo Inca. Esta situación impone limitaciones a las posibles interpretaciones de las lesiones registradas. Sin embargo, debido a que estas dos etapas están caracterizadas por una alta concentración poblacional (Albeck 1992; Nielsen 1996, 2001; Tarragó 2000), era de esperar observar una mayor frecuencia de lesiones atribuibles a violencia. Un aumento en la presión de población que habría desembocado en la necesidad de ocupar sitios estratégicos, desde los cuales se podían controlar y eventualmente defender tanto territorios como recursos, habría generado enfrentamientos tanto entre habitantes de los distintos asentamientos como respecto de eventuales intrusos procedentes de otras regiones ( $c f$. ., Kolata 1993).

En el estudio de Gheggi y Seldes (2012), donde se analizaron 423 cráneos provenientes de distintos sitios del NOA asignados por las autoras a los Desarrollos Regionales, se observó la presencia de lesiones traumáticas atribuibles a violencia en el $13.95 \%$ del conjunto. Si bien la prevalencia resultó mayor a la observada por nosotros, la misma sigue siendo marcadamente menor a la registrada en estudios similares llevados a cabo sobre sitios atacameños asignados al mismo momento cronológico (Lessa 2005; Torres-Rouff et al. 2005; Torres-Rouff y Costa Junqueira 2006). Estos resultados nuevamente sugieren que, si bien las situaciones de conflicto estaban establecidas en el NOA, éstas o no eran comparativamente $\tan$ frecuentes o se manifestaban de manera diferente a lo que al parecer sucedía en ámbitos transcordilleranos.

\section{Indicadores de violencia en el periodo Hispano- Indígena I}

En cuanto a las lesiones traumáticas ( $n=7$ ) observadas en los cráneos procedentes de La Falda, el agente más probable parece haber sido la violencia ejercida con armas o proyectiles de morfologías romas. Walker (1989) señala que, aunque las depresiones craneanas pueden ser una consecuencia de accidentes, es más probable que sean el resultado de situaciones de violencia. Las características morfológicas y la naturaleza no letal de las fracturas sugieren el empleo de armas tales como bastones de madera de extremos redondeados o guijarros pequeños lanzados con hondas. El hecho de que las lesiones se observen en individuos de ambos sexos (uno de los individuos que mostraba este tipo de lesiones era un femenino adulto mayor) podría estar sugiriendo tanto la existencia de eventos de violencia doméstica y/o intragrupo como la participación directa de las mujeres en los conflictos bélicos. Sin embargo, la frecuencia de hombres que manifestaron lesiones asociadas a violencia para este periodo fue significativamente mayor que la de mujeres. Adicionalmente, estas lesiones también podrían estar obedeciendo a enfrentamientos de índole ritual y/o simbólico-cíclicos generados hacia el interior del grupo o parcialidad.

Batallas rituales que tienen lugar en poblaciones andinas actuales, similares al denominado tinku (Bandelier 1910) y donde el objetivo sería herir y hacer sangrar al otro antes que provocarle la muerte (Orlove 1994), bien podrían haber tenido lugar en el NOA prehistórico. Sin embargo, la presencia de puntas cola de golondrina formando parte de las inclusiones funerarias de los individuos masculinos podría estar soportando la existencia individuos con estatus de guerrero reconocidos como tales hacia el interior de este poblado.

Los casos de violencia interpersonal de la cámara 13 de Rincón Chico 21 responderían a una situación muy distinta a la registrada en otros rasgos del mismo cementerio asignados a periodos anteriores. Durante los trabajos de campo se notó que en las cámaras en las cuales fueron hallados materiales correspondientes al periodo Hispano-Indígena I (C-1 nivel superior y C-13) se observan cambios significativos en los procedimientos funerarios (i. e., reutilización y preparación apresurada del espacio mortuorio con remoción no cuidada de inhumaciones anteriores y un empobrecimiento en la calidad de las inclusiones funerarias). Es posible que estas situaciones obedezcan a la existencia de factores generadores de tensión y disrupción social mencionados para las comunidades del valle (Mendonça et al. 2013). Trece de las 24 puntas de proyectil halladas en esta cámara se en 
contraban agrupadas en conjuntos dispuestos entre los individuos "I" y "II", sin tener relación alguna con los elementos óseos articulados o con los espacios que habrían estado ocupados por los tejidos blandos, por lo que se ha inferido que se trataban de puntas de proyectil que habrían sido incluidas a modo de acompañamiento junto con sus respectivos astiles. La comparación de las proporciones métricas entre tales puntas de proyectil y aquellas fehacientemente asociadas con eventos traumáticos demostró variaciones en el espesor y longitud que sugerirían diferencias en la tecnofactura y, potencialmente, en la adscripción grupal entre atacantes y atacados (Ammann 2007). Sin embargo, no nos es posible descartar la posibilidad de que se trate de situaciones de conflicto ocurridas entre miembros de parcialidades diferentes dentro del mismo poblado. De las 11 puntas de proyectil vinculadas directamente a eventos violencia, nueve de éstas estaban asociadas al individuo "I", mientras que las dos restantes se hallaron asociadas al individuo "II". Los proyectiles asociados al primer individuo habrían producido lesiones tanto en tejidos blandos como óseos, alcanzando a afectar a órganos vitales y poniendo gravemente en peligro la vida de la víctima, a la cual la muerte le habría sobrevenido rápidamente. La trayectoria y el alcance de penetración de estos proyectiles sugiere la existencia de una distancia relativamente próxima entre víctima y victimario/s, tratándose posiblemente de una ejecución a muy corta distancia. La total ausencia del antebrazo y mano derechos de este individuo constituye un hallazgo de difícil interpretación, ya que no se encontró ningún tipo de marca que indicara acciones de cercenamiento. Sólo es posible señalar que, en ausencia de otro indicador válido, de poder verificarse una desarticulación violenta, habría habido una suerte de ensañamiento hacia el cuerpo de este individuo en particular. En este sentido, cabe mencionar que la práctica de toma de trofeos y desmembramiento de extremidades superiores ha sido bien documentada en diferentes sitios de California (Andrushko et al. 2005, 2010) y generalmente no se los asocia con eventos aislados, sino con prácticas y estrategias de guerra (Andrushko et al. 2010). Sin embargo, y aunque lo consideramos como un hecho muy poco probable, tampoco podemos descartar que esta ausencia haya sido provocada por particulares procesos tafonómicos intracámara. Finalmente, las dos puntas de proyectil asociadas a violencia en el individuo "II" también le habrían provocado daños severos en sus órganos vitales. El proyectil que ingresó por la espalda habría afectado tanto a vasos como también al pulmón izquierdo. En cuanto al proyectil hallado en la cavidad abdominal, éste habría producido severos daños a órganos intraperitoneales. De considerar que el motivo de la muerte de estos individuos habría sido la existencia de un conflicto interétnico entre parcialidades aborígenes, es válido interpretar que durante tiempos hispano-indígenas también existieron situaciones de conflicto y tensión social dentro del ámbito del valle santamariano. Debido a la asignación cronológica de los entierros de la $\mathrm{C}-13$, estas situaciones de violencia pueden ser interpretadas tanto en un escenario de intentos fallidos de penetración imperial europea, donde la cercanía de los invasores y sus contingentes armados generaron tensiones que resultaron en eventos de violencia tanto entre pobladores del valle como con pobladores de regiones aledañas (González y Pérez 1972); como así también en un escenario donde el imperio incaico, aún con posterioridad al descabezamiento cuzqueño, todavía buscaba consolidarse $y / 0$ afianzarse en estos territorios. También es válido suponer la existencia de conflictos entre los diferentes señoríos regionales, posiblemente debido a situaciones de escasez de y/o competencia por determinados recursos, o, en su defecto, a raíz de la existencia de diferencias entre miembros de parcialidades hacia el interior del mismo ámbito del poblado de Rincón Chico.

En resumen, nuestros materiales estarían denotando un incremento de situaciones de violencia para el periodo Hispano-Indígena inicial, los que se verifican tanto en quebrada de Humahuaca como en el valle calchaquí meridional. Esta situación podría estar reflejando una situación de aumento de tensión social general para todo el NOA aún antes de que se estableciera el contacto directo con los europeos.

\section{* Conclusiones}

El relevamiento de traumas atribuibles a eventos de violencia interpersonal en los conjuntos óseos considerados para este estudio indica claramente que los episodios de violencia en las poblaciones agrícola-pastoriles del NOA se manifestaron tan tempranamente como en el Formativo Inferior y que tales eventos se evidencian de manera continua e ininterrumpida hasta momentos finales de la vida plenamente aborigen (Hispano-Indígena I). Los 
resultados obtenidos también sugieren que los individuos de sexo masculino se habrían visto mayormente involucrados en las situaciones de violencia.

Si bien en este trabajo no se observaron diferencias estadísticamente significativas entre los distintos periodos considerados, se observa una mayor frecuencia de traumas atribuibles a violencia en los materiales provenientes del Hispano-Indígena inicial respecto de las otras franjas temporales del desarrollo sociocultural. De este modo, es posible concluir que la existencia de episodios de violencia en el NOA constituyó un fenómeno generalizado y de notable perduración cronológica.

En función de las fuentes documentales actualmente disponibles, el conjunto de lesiones observadas respondería a un variado espectro de posibles causales de situaciones signadas por violencia, entre las que se consideran desde conflictos entre grupos foráneos por la defensa territorial y el acceso y aprovisionamiento de recursos hasta enfrentamientos armados entre individuos $y / o$ parcialidades intrapoblado, ya sea por la existencia de diferencias entre facciones étnicas específicas o debido a luchas rituales y/o simbólicas motivadas hacia el interior de los grupos.

Para los casos de Rincón Chico 21 asignables a contextos Inca e Hispano-Indígena I, las lesiones observadas podrían vincularse con posibles expansiones y/o penetraciones territoriales de grupos extra valle, incluyendo los contingentes imperiales, que podrían haber incrementado los niveles de violencia y tensión social entre las diferentes comunidades de los valles y quebradas considerados.

Si bien debemos reconocer que los materiales utilizados para la elaboración de este trabajo podrían adolecer de diferentes tipos de limitaciones y/o sesgos de representación (i. e; preservación diferencial de depósito y post-depósito, prácticas funerarias específicas, grado de representatividad probabilística de eventos reales de violencia ocurridos en las diferentes regiones consideradas, etc.), los autores consideran importante destacar que el desarrollo de estudios sistemáticos para la recuperación y registro de datos relacionados con los indicadores de violencia y/o tensión social constituye una fuente de valiosa información que potencia y enriquece notablemente nuestra visión y entendimiento de las dinámicas de las sociedades del pasado y sus interacciones.

\section{* Agradecimientos}

Este trabajo fue realizado en el marco del desarrollo del proyecto "Bioarqueología y Comportamiento Mortuorio en Sociedades Prehistóricas e Hispano-Indígenas de Contacto y Post Contacto Inicial" dirigido por dos de los autores (OJM y MAB), y ha contado con el apoyo financiero de las siguientes instituciones: CONICET, ANPCyT, MINCyT Pcia. de Córdoba, y CyTUNRC. Agradecemos a las autoridades de la Dirección de Antropología de Catamarca y Jujuy por otorgarnos los permisos de excavación correspondientes. Los autores expresan su muy especial agradecimiento a la Sra. Verónica Barbero, a la Srta. Melina Bottini y a la radióloga Blanca Oviedo por la dedicación y el esmero puestos de manifiesto en cada una de las imágenes que acompañan, ilustran y enriquecen este trabajo. Asimismo desean hacer expreso su profundo reconocimiento por las valiosas correcciones y/o sugerencias aportadas por los expertos revisores y evaluadores de la revista. Cualquier error u omisión resultan obviamente, de la exclusiva responsabilidad de los autores.

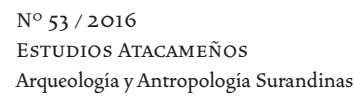




\section{$\leadsto$ Referencias citadas}

ALBECK, M. E. 1992. El ambiente como generador de hipótesis sobre dinámica sociocultural hispánica en la quebrada de $\mathrm{Hu}$ mahuaca. Cuadernos Facultad Humanidades y Ciencias Sociales, UNJu 3:95-106.

ALBECK, M. E.200o. La vida agraria en los Andes del sur. En Los pueblos originarios y la conquista. Nueva Historia Argentina, Tomo 1, editado por M. N. Tarragó, pp. 187-228. Editorial Sudamericana, Buenos Aires.

AMMANN, M. G. 2007. Trauma y Tensión Social en Rincón Chico 21 (SCatRCh21, Santa María, Catamarca). Estudio de Osteología humana. Tesis de Licenciatura inédita, Departamento de Cs. Naturales, Universidad Nacional de Río Cuarto, Río Cuarto.

ANDRUSHKO, V. A. y E. C. TORRES. 2011. Skeletal evidence for Inka warfare from the Cuzco region of Peru. American Journal of Physical Anthropology 146:361-372.

ANDRUSHKO, V. A., K. A. LATHAM, D. L. GRADY, A. G. PASTRON y P. L. WALKER. 2005. Bioarchaeological evidence for trophy taking in prehistoric central California. American Journal of Physical Anthropology 127: 375-384.

ANDRUSHKO, V. A.; A. W. SCHWITALLA y P. L. WALKER. 2010. Trophy-taking and dismemberment as warfare strategies in prehistoric central California. American Journal of Physical Anthropology 141: 83-96.

ASCHERO, C. 2000 . El poblamiento del territorio. En Los pueblos originarios y la conquista. Nueva Historia Argentina, Tomo 1, editado por M.N. Tarragó, pp. 17-59. Editorial Sudamericana, Buenos Aires.

BANDELIER, A. F. A. 1910. The islands of Titicaca and Koati. Hispanic Society of America, Nueva York.

BARRIENTOS, G. y F. GORDÓN. 2004. Explorando la relación entre nucleamiento poblacional y violencia interpersonal durante el Holoceno tardío en el noroeste de Patagonia (República Argentina). Magallania 32: 53-69.

BENNETT, W. 1946. The Atacameño. En Handbook of South American Indian, H. Julian y C. Steward (Eds.), pp. 599-619. Smithsonian Institution Press, Washington.

BORDACH, M. A. 2006. Interacciones étnicas e indicadores de desigualdad social en el Cementerio de La Falda (SJTil 43), Tilcara, Jujuy. Estudios Atacameños 31: 115-128.
BUIKSTRA, J. E. y D. H. UBELAKER. 1994. Standards for data collection from human skeletal remains. Arkansas Archeological Survey Research Series No 44, Fayetteville, Arkansas.

CAMPILLO, D. 2001. Introducción a la paleopatología. Ediciones Bellatera, Barcelona.

DÍAZ, I., G. BARRIENTOS y S. PASTOR. 2015. Conflicto y violencia en las sierras de Córdoba durante el periodo prehispánico: una discusión basada en información arqueológica y etnohistórica. En Condiciones de posibilidad de la reproducción social en sociedades prehispánicas y coloniales tempranas en las sierras pampeanas (República Argentina), J. Salazar (Comp.), pp. 84-108. Centro de Estudios Históricos Prof. Carlos S.A. Segreti, Córdoba.

FLENSBORG, G.A. 2011. Lesiones traumáticas en cráneos del sitio Paso Alsina 1. Explorando indicadores de violencia interpersonal en la transición Pampeano-Patagónica Oriental (Argentina). Intersecciones en Antropología 12: 45-59.

GHEGGI, M. S. y V. SELDES. 2012. Evidencias bioarqueológicas de conflicto ca. 1000-1432 AD en la quebrada de Humahuaca y el valle Calchaquí. Intersecciones en Antropología 13:103-115.

GONZÁLEZ, A. R. 1978. La presencia inca en el NOA. Tópicos. Revista de Ciencia y Térnica, Año 1, Nro. 1. Buenos Aires.

GONZÁLEZ, A. R.1980. Patrones de asentamiento incaico en una provincia marginal del Imperio. Implicancias socioculturales. Relaciones de la Sociedad Argentina de Antropología XIV (1): 63-82.

GONZÁLEZ, A. R.y J. A. PÉREZ. 1972. Historia Argentina. Argentina Indigena, vísperas de la Conquista. Colección Historia Argentina. Editorial Paidós, Buenos Aires.

GONZÁLEZ, L. R. y M. N. TARRAGÓ. 2004. Dominación, resistencia y tecnología: la ocupación incaica en el noroeste argentino. Chungara Revista de Antropología Chilena 36 (2):393-406

GONZÁLEZ BARONI, L. G. 2013. Bioarqueología del sector I del sitio Punta de la Peña 9: un entierro múltiple agropastoril. En Actas del XVIII Congreso Nacional de Arqueología Argentina, J.R. Bárcena y S. Martin (Eds.), pp.24. Universidad Nacional de La Rioja - CONICET, La Rioja.

GORDÓN, F. y G. GHIDINI. 2007. Análisis bioarqueológico de la violencia interpersonal. El valle inferior del río Negro (República Argentina) durante el Holoceno tardío. Werkén 9: 27-45. 
JURMAIN, R. 1999. Stories from the skeleton. Behavioral reconstruction in human osteology. Gordon and Breach, Amsterdam.

JURMAIN, R.2001. Paleoepidemiological patterns of trauma in a prehistoric population from central California. American Journal of Physical Anthropology 115: 13-23.

JURMAIN, R. y V. I. BELLIFEMINE. 1997. Patterns of cranial trau$\mathrm{ma}$ in a prehistoric population from central California. International Journal of Osteoarchaeology 7: 43-50.

JURMAIN, R., E. BARTELINK, A. LEVENTHAL, V. BELLIFEMINE, I. NECHAYEV, M. ATWOOD y D. DIGIUSEPPE. 2009. Palaeoepidemiological patterns of interpersonal aggression in a prehistoric central California population from CA-ALA-329. American Journal of Physical Anthropology 139: 462-473.

KOLATA, A. L. 1993. The Tiwanaku: portrait of an andean civilization. Wiley-Blackwell, Oxford y Cambridge.

KRAPOVICKAS, P. 1969. La instalación aborigen en "pucará de Yacoraite". Etnia 10: 8-12.

KRAPOVICKAS, P.1973. Costumbres funerarias de los pobladores prehispánicos del noroeste argentino. En Estudios dedicados a Luis Pericot, pp. 364-372. Universidad de Barcelona. Barcelona.

KRAPOVICKAS, P.1981-1982. Hallazgos incaicos en Tilcara y Yacoraite (una reinterpretación). Relaciones de la Sociedad Argentina de Antropología XIV (2): 67-80.

LESSA, A. 2005. Paleoepidemiologia dos Traumas Agudos em Grupos Atacamenhos: a Violencia sob uma Perspectiva Diacrônica. Tesis para optar al grado de Doctor en Ciencias, Escola Nacional de Saúde Pública Sérgio Arouca, Fundação Oswaldo Cruz, Rio de Janeiro.

LESSA, A. y S. MENDONÇA DE SOUZA. 2007. Gestación de un nuevo panorama social en el oasis atacameño: conflictos durante la transición para el período de las autonomías regionales. Chungara Revista de Antropología Chilena 39(2): 209-220.

LOVEJOY, C. O. y K. G. HEIPLE. 1981. The analysis of fractures in skeletal populations with an example from the Libben site, Ottawa County, Ohio. American Journal of Physical Anthropology $55: 529-541$.

LOVELL, N. 1997. Trauma analysis in Paleopathology. Yearbook of Physical Anthropology 40: 139-170.

MARTIN, D. L. y R. P. HARROD. 2015. Bioarchaeological contributions to the study of violence. Yearbook of Physical Anthropology 156: 116-145.
MENDONÇA, O. J., M. A. BORDACH, M. S. RUIZ y M. B. CREMONTE. 1991. Nuevas evidencias del Temprano en quebrada de Humahuaca. Los hallazgos del sitio Til 20 (Tilcara, Jujuy). Revista Comechingonia 8(7): 29-48.

MENDONÇA, O. J., M. A. BORDACH, M. E. ALBECK y M. S. RUIZ. 1997. Collares de vidrio y ollas de barro. Comportamiento ante la muerte en el Tilcara Hispanoindígena Inicial (Jujuy, Argentina). Cuadernos Facultad Humanidades y Ciencias Sociales, UNJu 9: 175-202.

MENDONÇA, O. J., M. A. BORDACH y M. V. GROSSO. 2003. Ocupación territorial y control e intercambio en el período Hispano-Indígena. Estudio comparado de los cementerios de RCh 21 (Catamarca) y SJ Til 43 (Jujuy). Cuadernos Facultad Humanidades y Ciencias Sociales, UNJu 20: 221-237.

MENDONÇA, O. J.; M. A. BORDACH y M. A. ARRIETA. 2013. El comportamiento mortuorio en Til 43 y RCh 21 del tardío al Hispano-Indígena: Continuidades, transformaciones y rupturas materiales y simbólicas. Perspectiva regional. Pacarina. Arqueología y Etnografía Americana 7: 67-82.

MERBS, C. F. 1989. Trauma. En Reconstruction of life from the skeleton, editado por M.Y. Iscan y K.A. Kennedy, pp. 161-189. Alan R. Liss, Nueva York.

MILNER, G., E. ANDERSON y V. SMITH. 1991. Warfare in late prehistoric west-central Illinois. American Antiquity 56:581-603.

MURPHY, M. S., C. GAITHER, E. GOYCOCHEA, J. W. VERA$\mathrm{NO}$ y G. COCK. 2010. Violence and weapon-related trauma at Puruchuco-Huaquerones, Peru. American Journal of Physical Anthropology 109: 253-258.

NIELSEN, A. E. 1996. Demografía y cambio social en la quebrada de Humahuaca (Jujuy, Argentina) 700-1535 DC. Relaciones de la Sociedad Argentina de Antropología XXI: 307-354.

NIELSEN, A. E. 2001. Evolución social en quebrada de Humahuaca (AD700-1536). En Historia Argentina Prehispánica, Tomo 1, E. E. Berberián y A. E. Nielsen (Eds.), pp. 171-264. Editorial Brujas, Córdoba.

NIELSEN, A. E. 2009. Ancestors at war. En Warfare in cultural context. Practice, Agency, and the Archaeology of Violence, A. E. Nielsen y W. H. Walker (Eds.), pp. 218-243. Amerind Studies in Archaeology Vol. 3 . The University of Arizona Press, Tucson.

NÚÑEZ, L. y T. S. DILLEHAY. 1995. Movilidad giratoria, armonía social y desarrollo en los Andes Meridionales: patrones de tráfico e interacción económica. Universidad Católica del Norte, Antofagasta. 
ORLOVE, B. 1994. Sticks and stones: ritual battles and play in the southern Peruvian Andes. En Unruly order: violence, power, and cultural identity in the high provinces of southern Peru, editado por D. Poole, pp. 133-164. Westview Press, Boulder.

OTERO, C. 2013. Producción, usos y circulación de bienes en el Pucará de Tilcara (quebrada de Humahuaca, Jujuy). Tesis Doctoral inédita. Facultad de Filosofía y Letras, Universidad de Buenos Aires, Buenos Aires.

OTTONELLO, M. M. y A. M. LORANDI. 1987. Introducción a la arqueología y etnología. Diez mil años de historia argentina. EUDEBA, Buenos Aires.

RAFFINO, R. 1981. Los Inkas del Kollasuyu, 2da. ed. Ramos Americana Editora, La Plata.

SAUER, N. 1998. The timing of injuries and manner of death: distinguishing among antemortem, perimortem, and postmortem trauma. En Forensic osteology, K. Reichs (Ed.), pp. 321-332. Charles, Thomas Springfield.

SCHJULTING, R. J. y M. WYSOCKI. 2005. "In this chambered tumulus were found cleft skulls...": an assessment of the evidence for cranial trauma in the British Neolithic. Proceedings of the Prehistoric Society 71: 107-138.
STANDEN, V. G. y B. T. ARRIAZA. 2000. Trauma in the preceramic coastal populations of northern Chile: Violence or occupational hazards? American Journal of Physical Anthropology 112: 239-249.

TARRAGÓ, M. N. 2000. Chacras y pukara. Desarrollos sociales tardíos. En Los pueblos originarios y la conquista. Nueva Historia Argentina, Tomo 1, M. N. Tarragó (Ed.), pp. 257-300. Editorial Sudamericana, Buenos Aires.

TORRES-ROUFF, C. y M. A. COSTA-JUNQUEIRA. 2006. Interpersonal violence in prehistoric San Pedro de Atacama, Chile: behavorial implications of enviromental stress. American Journal of Physical Anthropology 130: 60-70.

TORRES-ROUFF, C., M. A. COSTA-JUNQUEIRA y A. LLAGOSTERA. 2005. Violence in times of changes: the late intermediate period in San Pedro de Atacama. Chungara Revista de Antropología Chilena 37(1): 75-83.

WALKER, P. 1989. Cranial injuries as evidence of violence in prehistoric southern California. American Journal of Physical Anthropology $80: 313-323$.

WALKER, P.2001. A bioarchaeological perspective on the history of violence. Annual Review of Anthropology 30: 573-596.

WILLIAMS, V. I. 2000. El imperio Inka en la provincia de Catamarca. Intersecciones en Antropología 1: 55-78. 